\title{
Ergenlerde İntihar Olasılığı: Benlik Saygısı ve Öfke Açısından Íncelenmesi ${ }^{1}$
}

\author{
DOI: 10.26466/opus.528723 \\ * \\ Fulya Cenkseven Önder*- Ayten Bölükbaş̧ ${ }^{* *}$ \\ * Doç. Dr, Çukurova Üniversitesi, Eğitim Fakültesi, Adana / Türkiye \\ E-Posta: fulyac@cu.edu.tr \\ ORCID: 0000-0001-9748-626X \\ ** Doktora Öğrencisi, Çukurova Üniversitesi, Eğitim Fakültesi, Adana /Türkiye \\ E-Posta: ayten.bolukbasi2@gmail.com \\ ORCID: $\underline{0000-0003-4102-3906}$
}

Öz

Araştırmada (a) ergenlerde intihar olasılı̆̆ının, benlik saygısı, sürekli öfke, içe yönelik öfke, dışa yönelik öfke ve öfkenin kontrolü arasındaki ilişkileri ve (b) benlik saygısı, sürekli öfke, içe yönelik öfke, dışa yönelik öfke ve öfkenin kontrolünün intihar olasıliğııı ne düzeyde yordadığını incelemek amaçlanmıştır. Araştırmada "İntihar Olasıllğgl Ölçeği", "Rosenberg Benlik Saygısı Ölçeği" ve "Sürekli Öfke ve Öfke Iffade Tarzları Ölçeği" kullanılmıştır. Araştırma 214 kadın (\%50.2), 212 erkek (\%49.8) olmak üzere toplam 426 lise öğrencisi üzerinde gerçekleştirilmiştir. Çalışma grubunda yer alan öğrenciler 15-18 yaş aralığında olup, yaş ortalamaları 15.89'dur ( $S$ s=.85). Araştırmada değişkenler arası ilişkileri belirlemek üzere Pearson Çarpım Momentler Korelasyon analizi ve çoklu doğrusal regresyon analizi kullanılmıştır. Araştırma sonucunda intihar olasılığı ile benlik saygısı ve öfke kontrolü arasında negatif yönde; benlik saygısı sürekli öfke, içe ve dışa yönelik öfke arasında ise pozitif yönde anlamlı ilişkiler belirlenmiştir. Regresyon analizi sonucunda öfke kontrolü değişkeni dışındaki tüm değişkenlerin intihar olasılığının anlamlı yordayıcıları olduğ u belirlenmiştir.

Anahtar Kelimeler: İntihar olasılığı, Benlik saygısı, Öfke, Öfke ifade tarzları

\footnotetext{
${ }^{1}$ Bu çalışmanın bir bölümü 13-15 Eylül 2018 tarihleri arasında düzenlenen I. Uluslararası Eğitimde ve Kültürde Akademik Çalışmalar Sempozyumu'nda sunulmuştur.
} 


\title{
Suicide Probability in Adolescents: Relationship to Self-Esteem, and Anger
}

\begin{abstract}
The aim of this study is to examine the relationships between suicide probability, self-esteem, trait-anger, anger-in, anger-out and anger control and also to reveal the predictive power of self-esteem, trait-anger, and anger-in, anger-out and anger control on suicide probability among adolescents. In this research, "Suicide Probability", "Rosenberg Self-Esteem Scale", and "The State-Trait Anger Scale" were used. This research was conducted on 426 high school students (214 females, 50.2\%; 212 males, 49.8\%). Participants ranged in age between 15 and 18 years and mean age of the participants was 15.89 (sd=.85). Pearson correlational analysis and multiple linear regression were conducted to reveal the relationships between study variables. According to research results, it was concluded that suicide probability was negatively correlated with self-esteem and anger control, whereas it was positively correlated with trait anger, anger-in, anger-out. Also, all variables of the research apart from anger control were found to be a significant predictor of suicide probability among adolescents in present study.
\end{abstract}

Keywords Suicide probability, Anger, Self-esteem, Anger expression styles 


\section{Giriş}

Birçok psikolojik, sosyolojik, ekonomik ve kültürel faktörlerin sonucundan etkilenebilen çok yönlü bir davranış olarak tanımlanan intihar, ölüm niyeti ile bilinçli kendine zarar verme olarak ifade edilmektedir (Hjelmeland vd., 2002). İntihar olasılığı ise umutsuzluk, intihar düşüncesi, düşmanlık ve olumsuz kendilik değerlendirmesi şeklinde alt boyutları ile intihar riskini değerlendiren bir kavramdır (Cull ve Gill, 1990).

İntihar çalışmaları ile ilgili ön plana çıkan ve aslında birçok ülkede karşılaşılan sorunlardan biri intihar yaygınlığının tam olarak raporlanamamasıdır (Waseserman, Cheng ve Jiang, 2005). Türkiye açısından ölümle sonuçlanan intihar sayısının güncel verilere göre, 2015 yılında \%1.3 artış göstererek 3211 kişi olduğu ve yaş grubuna göre incelendiğinde ise \%34.3'ünü 15-29 yaş grubundaki kişilerden meydana geldiği rapor edilmiştir. Cinsiyet değişkenine göre ölümle sonuçlanan intihar oranları incelendiğinde, kadınların intihar etmelerindeki oran \%18 ile 15-19 yaş aral1ğındayken erkeklerin en fazla intihar etme oranı \%12.8 ile 20-24 yaş aral1ğında olduğu tespit edilmiştir. Sonuç olarak, intihar eden erkeklerin \%33.3'ünün, kadınların ise \%46'sının 30 yaşından küçük olduğu belirlenmiştir (TÜİK, 2015). Dünya genelinde ise önde gelen ölüm nedenleri arasında yer alan intihar, 15 ila 29 yaş arasındaki gençlerin ikinci sıradaki ölüm nedeni olarak raporlanmıştır (WHO, 2017). İntihar düşüncelerinden gerçek bir intihar girişimi planları arasında değişkenlik gösteren ve aynı zamanda intihar olasılığının bir alt boyutu olan intihar düşüncelerinin, ergenlerde dünya genelinde görülme sıklı̆̆ının \%15 ile \%25 arasında olduğu ifade edilmektedir (Bridge, Goldstein ve Brent, 2006).

İntihar ile ilgili davranışlar okul çağındaki ergenler arasında yaygın görülmektedir. Lise dönemini kapsayan ergenlik dönemi, beden ve kişiliklerini etkileyen fiziksel, duygusal, sosyal değişim ve gelişimin gerçekleştiği bir gelişim dönemidir (Orbach, Mikulincer, Gilboa-Schechtman ve Sirota, 2003). Çocukluk dönemi ile kıyaslandığında ergenlik dönemindeki ruh sağlığı sorunlarında artış görülmektedir (Kim, 2003). Bu nedenle, karmaşık ve ciddi toplumsal sağlık problemlerinden biri olan intiharın, ergenlere yönelik benlik saygısı, sürekli öfke ve öfke ifade tarzlarının intihar olasılığını yordama gücüne ilişkin betimsel bilgiler sunmanın gelecekte 
planlanacak betimsel çalışmalar ve intiharı önlemeye yönelik programların hazırlanması için faydalı olacağı düşünülmektedir.

Kişiliğin önemli bir boyutu olan ve intihar olasılığının önemli koruyucu faktörleri arasında olduğu düşünülen benlik sayg1sı, Rosenberg (1965) tarafından, bireyin benlik kavramına ilişkin kendini değerlendirmesi sonucu olarak ulaştığı "değerlilik" yargısı olarak tanımlanmıştır. Benzer şekilde, Coopersmith (1967) benlik saygısını bireyin kendi saygınlığı ile ilgili yaptığı bir değerlendirme şeklinde tanımlamış ve bireyin kendi yeterlilik, önem, başarı ve değerlerine ilişkin inancının ve kendini onaylama ya da onaylamama tutumunun bir ifadesi olarak belirtmiştir. Örneğin, yüksek benlik saygısı kişinin kendini değerli gördüğünü, düşük benlik saygısı ise kişinin kendisine saygı duymadığı ve bununla birlikte kendini değersiz, yetersiz ya da eksik olarak değerlendirdiğini yansıtmaktadır (Rosenberg, 1979). Özellikle düşük benlik saygısına sahip genç bireyler, kendilerine yönelik olumsuz benlik kavramına ilişkin stres yaratan biliş ve duygularından kaçış olarak intiharı düşünebilmektedir (Baumeister, 1990; Harter, 2012). Bu yönüyle, benlik saygısının yaşamdaki stres kaynaklarına karşı ve intihar düşüncelerine yönelik önemli bir koruyucu faktör olduğu ifade edilmektedir (Jang vd., 2014). Birçok araştırmada, düşük benlik saygısının intihar düşüncesinin artmasında etkili olduğu görülmüştür (Bernstein-Duprey, Oshri ve Liu, 2018; Bhar, GhahramanlouHolloway, Brown ve Beck, 2008; Jang vd., 2014; Wild, Flisher ve Lombard, 2004). Bunun yanı sıra, 55 ülkenin dahil edildiği bir çalışmada benlik saygısının görece daha düşük olduğu ülkelerde daha fazla intihar yaygınlığ1nın göze çarptığı rapor edilmiştir (Chatard, Selimbegović ve Konan, 2008).

İntihar davranışları altında yatan birçok karmaşık ve birbiriyle ilişkili olabilecek risk faktörleri bulunmaktadır. Özellikle ortaokuldan lise kademesine geçen ergenlerin uyum sağlaması gereken birçok akademik, sosyal, gelişimsel alanlar bulunmakla birlikte her ergenin bu dönemlere sağlıklı biçimde uyum sağlamada başarılı olamaması risk faktörlerinin ortaya çıkmasını tetiklemektedir (Westefeld vd., 2006). Örneğin; depresyon, kuraldışı davranışlar, okuldan atılma (Vajani vd., 2007), zorbalık (Hinduja ve Patchin, 2010) madde ve alkol kullanımı, aile ile çatışmalar, yakın arkadaşlar ile ilişki çatışmaları (Moskos, Olson, Halbern, Keller ve Gray, 2005), etkisiz başa çıkma (Cenkseven Önder, 2018; Kim ve Kim, 2008), kavgaya dahil olma ve zorbalığa maruz kalma (Silva, Santos, Soares ve Pardono, 
2014), fiziksel şiddet sonucu yaralanma (Sharma, Lee ve Nam, 2017) gibi etmenler intihar davranışlarıyla pozitif yönde ilişkili bulunan risk faktörlerindendir. Bu araştırmada düşük benlik saygısı yanısıra öfke kavramı da intihar eğilimi için risk faktörlerinden biri olarak ele alınmıştır.

Ergenlik döneminde ciddi ve yaygın olarak görülen ve intihar olasılığ 1 ile ilişkili olan öfke hem bireysel, hem de toplum boyutunda olumsuz sonuçlara neden olabilmektedir (Yount, 2000). Öfke, olumsuz uyaranları sonlandırma arzusuna yönelik bilişsel sürece eşlik eden ve bireyin gerçek veya da zihinsel tasarımındaki engellenme, tehdit veya haksızlığa verdiği tepki olarak oluşan güçlü bir duygu veya deneyim durumu olarak tanımlanmaktadır (Biaggio ve Maiuro, 1985). Ergenlerin evdeki, okuldaki ve toplumdaki zorunluluk ve sorumluluklara ilişkin verdiği yaygın tepkilerden (Patterson ve Hastings, 2007) olan öfke, sıklığ1 ve yoğunluğuna göre sürekli ve durumluk olarak ayrılmaktadır. Durumluk öfke, acil durumlarda verilen tepki ile meydana gelen, yoğunluğu değişebilen, kısa dönemde dalgalanmalar gösteren duygusal ve fizyolojik yaşantılar iken; sürekli öfke, durumluk öfke yaşama eğilimi veya öfke yatkınlığının durağan şekilde yansıtılması olarak ifade edilmektedir. Bunun yanı sıra, sürekli öfkenin artışı bireyin daha sık ve daha yoğun durumluk öfke yaşadığına işaret etmektedir (Deffenbacher, Lynch, Oeting ve Kemper, 1996). Sürekli öfke duygusunu yüksek seviyede deneyimlemek, sağlık problemlerine, eğitim ve iş yaşamındaki güçlüklere ve kişilerarası ilişkilerin zarar görmesine ve benlik saygisının azalmasına neden olabilmektedir (Dahlen ve Martin, 2005).

Spielberger'e (1983) göre, bireyler öfkelerini içte tutma, dışa vurma ve kontrol etme biçiminde olmak üzere üç şekilde ifade etme tarzına sahiptir. İçte tutulan öfke, öfkeli düşünme ve duygulanımları bastırma eğilimini yansıtırken öfkenin dışa vurulması, dış dünyadaki obje ya da canlılara yöneltilerek saldırma içeren davranışlara dönüşme eğilimini yansıtmaktadır. Son olarak öfkenin kontrolü ise öfke duygusunun çıkmasını önleme, bastırma, mantığa bürünme gibi savunmalarla kontrol sağlama eğilimi olarak ifade edilmektedir. Öfke, doğal bir duygu tepkisi olsa da ergenlerin öfke ile ilgili temel problemi öfkeyi uygun bir şekilde ifade edecek ve yönetecek gerekli beceri ve kaynaklara yeterince sahip olamamasıdır (Lee, Choi, Kim, Park ve Shin, 2009). 
Uygun bir şekilde ifade edilmemiş öfke, ergenlerde psikolojik, fiziksel ve sosyal sorunları beraberinde getirmektedir (Starner ve Peters, 2004). Bireylerin, duygularının yıkıcı bir biçime dönüşmesi ve hatta kendini suçlama ve kendine zarar verme davranışlarının ortaya çıkışı (Fox ve Hawton, 2004) öfkenin bastırılması ve içselleştirilmesi aracılığıyla gerçekleşebilmektedir (Lee ve Mokuah, 2002). Öfke düzeyi yüksek genç bireyler, yoğun düzeyde içsel çatışmalar ve problemler yaşayabilmektedir. Bireyler, öfke nedeniyle kendilerine, diğerlerine ve nesnelere zarar verme; başarısız kişilerarası ilişkilere, okul ve işte problemlerine ve daha düşük özsaygıya sahip olma eğilimindedir (Deffenbacher, Lynch, Oeting ve Kemper, 1996). Alanyazında yapılan çalışmalarda, öfkenin ergenlerde intihar davranışlarının yordayıcısı olduğu (Kirkcaldy, Siefen, Urkin ve Merrick, 2006) öfke ve öfke ifade biçiminin intihar ihtimali (Reyes vd., 2015) ve intihar düşüncesi (Park vd., 2010) ile ilişkili olduğu ortaya konulmuştur.

İntihar nedeni ile yaşamını kaybeden gençlerin sayısındaki artış nedeni ile Dünya Sağlık Örgütü, intihar davranışlarının engellenmesinde gençlerin yüksek düzeyde riskli yaş grubu olarak değerlendirilmesinin önemine vurguda bulunmuştur (WHO, 2012). Dünya Sağlık Örgütü raporunda (2014) intiharın önlenebilir bir durum olmasına rağmen dünya genelinde yaygın rastlanan güncel bir sağlık sorunu olduğu ifade edilmiştir. Buradan hareketle, bu çalışma ile ergenlerin intihar olasılı̆̆ının ve intihar olasılığı ile ilişkili olabilecek etmenlerin incelenmesinin ruh sağlığı alanlarında hizmet veren koruyucu ve önleyici intihar araştırma ve uygulamalarda bulunacak uzmanlara katkı sağlayabilecektir. Ayrıca, yurtiçi alanyazınında ergenlerde intihar olasılığının öfke ve benlik saygısı değişkenlerinin yordayıcısı olarak birlikte incelendiği çalışmaların olmamasının bu çalışmayı yurtiçi alan yazını açısından önemli kıldığı düşünülmektedir. Tüm bu açıklamalar ışığında, bu araştırmanın amacı (a) ergenlerde intihar olasılığı ile benlik saygısı, sürekli öfke, içe yönelik öfke, dışa yönelik öfke ve öfkenin kontrolü arasındaki ilişkileri ve (b) benlik saygısı, sürekli öfke, içe yönelik öfke, dişa yönelik öfke ve öfkenin kontrolünün ergenlerin intihar olasılığını ne düzeyde yordadığını incelemektir. 


\section{Yöntem}

\section{Araştırmanın Modeli}

Bu çalışma ergenlik döneminde olan lise öğrencilerinin intihar olasılı̆̆ııın benlik saygısı ve öfke ile ilişkili olup olmadığının, intihar olasılığının benlik saygısı ve öfke tarafından yordanıp yordanmadığının belirlenmesine yönelik betimsel bir çalışma olup, ilişkisel tarama modeline dayalı olarak gerçekleştirilmiştir. Araştırmanın bağımlı değişkeni intihar olasılı̆̆ı, bağımsız değişkenleri ise benlik saygısı, sürekli öfke ve öfke ifade tarzlarıdir.

\section{Çalışma Grubu}

Araştırmanın çalışma evrenini Adana ili merkez ilçelerinde (Seyhan, Çukurova, Yüreğir, Sarıçam) yer alan devlet liselerine devam eden öğrenciler oluşturmaktadır. Araştırmanın çalışma grubu ise Adana ili merkez ilçelerinde yer alan dört liseye devam eden 214 k1z (\%50.2), 212 erkek (\%49.8) olmak üzere toplam 426 öğrenciden oluşmaktadır. Öğrenciler 14-18 yaş aralığında olup, yaş ortalamaları $15.89^{\prime}$ dur (Ss=.85). Çalışmaya katılan öğrencilerin 128'i 9. (\%30), 122’si 10. (\%28.6), 100’ü 11. (\% 23.5) ve 76’s1 12. (\%17.8) sınıfa devam etmektedir. Çalışma grubu, amaçlı örnekleme yöntemlerinden kolay ulaşılabilir durum örneklemesine göre oluşturulmuş olup, Adana ilinin dört merkez ilçesinden birer okul seçilmiştir. Belirlenen okullarda her sınıf düzeyinden bir sınıf rastgele belirlenmiş ve bu sınıflardaki gönüllü öğrencilere uygulama yapılmıştır.

\section{Veri Toplama Araçları}

Intihar Olasılı̆̆ı Ölçeği: Ergen ve yetişkinlerin intihar olasılıklarını belirlemek için Cull ve Gill (1990) tarafından geliştirilmiş olan ölçek, Tuğcu (1996) tarafından Türkçeye uyarlanmıştır. Ölçek 36 maddeden oluşmakta olup dört alt ölçeğe sahiptir: Umutsuzluk, intihar düşüncesi, olumsuz kendini değerlendirme ve düşmanlık. Dörtlü Likert türünde olan ölçek hiçbir zaman (1) dan her zaman (4) olacak şekilde puanlanmaktadır. Ölçek, intiharın davranışsal, bilişsel ve duyuşsal boyutlarını ortaya koyarak 
intihar riskini değerlendirmeyi amaçlamaktadır. Ölçekten alınan puan artması intihar olasılığının artışını yansıtmaktadır. Tuğcu (1996) Türkçe formun Cronbach's alfa güvenirlik katsayılarını her bir alt ölçek için .49 ve .75 arasında, toplam puan için ise .87 olarak belirlemiştir .

Rosenberg Benlik Saygısı Ölçeği: Ölçek Rosenberg (1965) tarafından geliştirilmiş olup, Çuhadaroğlu (1986) tarafından Türkçeye uyarlanmıştır. Toplam 63 sorudan oluşan ölçek 12 alt kategoriye sahiptir. Bu araştırmada öğrencilerin benlik saygısı düzeylerini belirlemek için ölçeğin Benlik Saygisı alt boyutuna ait ilk 10 madde kullanılmıştır. Rosenberg (1965) Benlik Saygısı Ölçeği alt boyutları için test tekrar test güvenirlik katsayısının .82 - .88 ve iç tutarlık katsayısının.77-.88 arasında değiştiğini belirlemiştir. Çuhadaroğlu (1986) Türkçe formun test-tekrar test güvenirlik katsayısının .48-.79 arasında değiştiğini saptamıştır.

Sürekli Öfke ve Öfke İfade Tarzları Ölçeği: Spielberger (1983) tarafından geliştirilmiş olan ölçek Türkçeye Özer (1994) tarafından uyarlanmıştır. Ölçek 4'lü Likert türünde olup 34 maddeden oluşmaktadır. Ölçeğin ilk 10 madde sürekli öfke düzeyini ölçmekte iken, 24 madde öfke ifade tarzlarını (öfke-içte, öfke-dışa ve öfke-kontrol alt boyutları) belirlemektedir. Özer (1994) Tükçe formun Cronbach alfa katsayılarını 'sürekli öfke' alt ölçeği için .67-.92, 'öfke dişa vurumu' alt ölçeği için .58-.76, 'öfke içe vurumu' boyutu için .80-.90, 'öfke kontrolü' boyutu için .69-.91olarak belirlemiş

\section{Verilerin Toplanmasi}

Gerekli izinler alındıktan sonra uygulama yapılacak okulların okul müdürleri ve okul psikolojik danışmanlarına bilgi verilmiş ve hangi gün uygulama yapılacağı kararlaştırılmıştır. Uygulama sırasında öğrencilere toplanan verilerin ve verecekleri cevapların samimi olmasının önemi anlatılmıştır. Yalnızca gönüllü öğrencilerden veri toplanmıştır. Uygulamalar yaklaşık 30 dakika sürmüştür. Uygulama sırasında 468 öğrenciye ulaşılmış; bunlardan 42 tanesi samimi yanıtlanmadığı ve boş madde sayısının fazla olması nedeniyle analiz dışı bırakılmış olup, toplam 426 tanesi analize dahil edilmiştir. 


\section{Verilerin Analizi}

Araştırmada değişkenler arasındaki ilişkileri belirlemek için Pearson Momentler Çarpımı Korelasyon Katsayısı, intihar olasılığının benlik saygısı, sürekli öfke, içe yönelik öfke dışa yönelik öfke ve öfke kontrolü tarafından ne düzeyde yordandığını belirlemek için ise çok değişkenli regresyon analizi kullanılmıştır. Regresyon analizi yapılmadan önce çarpıklık ve sivrilik değerlerine bakılmıştır. Değişkenlerin çarpıklık değerlerinin -.20 ile .68 arasında, sivrilik değerlerinin ise .05 ile -.46 arasında değiştiği saptanmış, saptanan değerler +1.5 ve -1.5 değerleri arasında oldukları için (Tabachnick ve Fidell, 2013) hiçbir değişkenin dönüştürülmesine gerek olmadığı görülmüştür. Her bir öğrenci için belirlenen Mahalanobis uzaklık değerleri $\mathrm{p}<.001$ ölçüt alınarak incelenmiş ve örneklemde "doğrusallık ve "normallik" sayıltılarının zedelenmesine neden olacak uç değerlerin olmadığ görülmüştür. Ayrıca tolerans ve varyans şişme değerleri (VIF) incelendiğinde çoklu eş doğrusallık (multicollinearity) probleminin olmadığı görülmüş̧ür. Bulguların anlamlı olup olmadığının yorumlanmasında .05 anlamlılık düzeyi ölçüt alınmıştır. Toplanan veriler SPSS-WINDOWS 22 paket programıla çözümlenmiştir.

\section{Bulgular}

Lise öğrencilerinde intihar olasılığı, benlik saygısı, öfke ve öfke ifade tarzları arasındaki ilişkileri incelemek amacıyla Pearson Momentler Çarpımı Korelasyon Katsayısı hesaplanmıştır. Tablo 1'de değişkenlerin aritmetik ortalamaları, standart sapma değerleri ve değişkenler arasındaki korelasyon değerleri yer almaktadır.

Tablo 1'de de görülebileceği gibi intihar olasıllğ̆ ile benlik saygısı ( $\mathrm{r}=-$ $.56, \mathrm{p}<.001)$ ve öfkenin kontrolü $(\mathrm{r}=-.26, \mathrm{p}<.001)$ arasında negatif yönde anlamlı ilişkiler vardır. İntihar olasılığı ile sürekli öfke (r=.49, p<.001), içe yönelik öfke $(\mathrm{r}=.48, \mathrm{p}<.001)$ ve dışa yönelik öfke $(\mathrm{r}=.48, \mathrm{p}<.001)$ arasında ise pozitif yönde anlamlı ilişkiler belirlenmiştir. 
Tablo 1. Değişkenler arasındaki korelasyonlar

\begin{tabular}{lllllll}
\hline & \multicolumn{1}{c}{$\mathbf{1}$} & $\mathbf{2}$ & $\mathbf{3}$ & $\mathbf{4}$ & $\mathbf{5}$ & $\mathbf{6}$ \\
\hline 1. İntihar olasılı̆̆1 & - & & & & & \\
2. Benlik saygısı & $-.56^{* *}$ & - & & & & \\
3. Sürekli öfke & $.49^{* *}$ & $-.27^{* *}$ & - & & & \\
4. İçe yönelik öfke & $.48^{* *}$ & $-.34^{* *}$ & $.51^{* *}$ & - & & \\
5. Dişa yönelik öfke & $.48^{* *}$ & $-.23^{* *}$ & $.69^{* *}$ & $.56^{* *}$ & - & \\
6. Öfke kontrol & $-.26^{* *}$ & $.31^{* *}$ & $-.34^{* *}$ & $-.10^{*}$ & $-.35^{* *}$ & - \\
x & 70.67 & 19.32 & 23.77 & 16.05 & 16.84 & 19.89 \\
Ss & 16.40 & 4.36 & 6.58 & 3.94 & 4.80 & 4.49 \\
\hline
\end{tabular}

${ }^{*} \mathrm{p}<.05,{ }^{* *} \mathrm{p}<.001$

Ergenlerin intihar olasılıklarını benlik saygısı, sürekli öfke, içe yönelik öfke, dışa yönelik öfke ve öfke kontrolü değişkenlerinin ne düzeyde yordadığını incelemek amacıyla çoklu regresyon analizi yapılmıştır. Tablo 2 'de ergenlerde intihar olasılığının yordayıcılarına ilişkin regresyon analizi sonuçları yer almaktadır.

Tablo 2. Intihar olasılı̆̆ını yordanmasına ilişkin regresyon modeli

\begin{tabular}{lcccc}
\hline \multicolumn{1}{c}{$\begin{array}{c}\text { Yordayıc1 } \\
\text { Değişkenler }\end{array}$} & B & Standart Hata & Beta & t \\
\hline Sabit & 69.81 & 5.21 & - & $13.40^{* *}$ \\
Benlik sayg1sı & -1.61 & .15 & -.43 & $-10.96^{* *}$ \\
Sürekli öfke & .43 & .13 & .17 & $3.41^{* *}$ \\
İçe yönelik öfke & .60 & .19 & .14 & $3.15^{*}$ \\
Dişa yönelik öfke & .65 & .18 & .19 & $3.56^{* *}$ \\
Öfke kontrol & .06 & .15 & .02 & .41 \\
\hline $\mathrm{R}=.70$ & $\Delta \mathrm{R}^{2}=.48$ & & & \\
$\mathrm{~F}(5,425)=79.12$ & $\mathrm{p}=.000$ & & &
\end{tabular}

Tablo 2 incelendiğinde benlik saygısı, sürekli öfke, içe yönelik öfke, dışa yönelik öfke ve öfkenin kontrolü değişkenlerinin lise öğrencilerinin intihar olasılıklarını anlamlı düzeyde açıladığı görülmektedir $\left(\Delta \mathrm{R}^{2}=.48\right.$, $\mathrm{p}<.001)$. Bu beş değiş̧ken birlikte, intihar olasılığının toplam varyansının \%48'ini açıklamaktadır. Standardize edilmiş regresyon katsayılarına göre, yordayıcı değişkenlerin intihar olasılığı üzerindeki göreli önem sırası; 
benlik saygısı ( $(=-.43)$, dışa yönelik öfke $(ß=.19)$, sürekli öfke $(\Omega=.17)$, içe yönelik öfke $(\Omega=.14)$ ve öfke kontrolüdür $(\Omega=.02)$. Regresyon katsayılarının anlamlılığına ilişkin t-testi sonuçları incelendiğinde ise, öfkenin kontrolü değişkeni ( $t=.41, p>$.05) dışındaki tüm değişkenlerin intihar olasılığının anlamlı yordayıcıları olduğu belirlenmiştir.

\section{Tartışma, Sonuç ve Öneriler}

Ergenlerin intihar olasılığının yordayıcıları olarak benlik saygısı, sürekli öfke, içe yönelik öfke, dişa yönelik öfke ve öfke kontrol değişkenlerinin incelendiği bu çalışmada intihar eğilimi ve benlik saygısı ile öfke kontrol değişkenleri arasında negatif yönlü; benlik saygısı, sürekli öfke, içe yönelik öfke ve dışa yönelik öfke arasında ise pozitif yönlü ilişkiler bulunmuş ve bu değişkenlerin (öfke kontrolü dışında) intihar olasılığının anlamlı yordaycıları olduğu görülmüştür. Mevcut araştırmadan elde edilen bu sonuçların, alanyazındaki intihar düşüncesi (Bhar vd., 2008; Creemers, Scholte, Engels, Prinstein ve Wiers, 2012; McGee vd., 2001;Wilburn ve Smith; 2005) intihar düşüncesi ve girişimi (Eskin, Ertekin, Dereboy ve Demirkıran, 2007; Kuhlberg, Pena ve Zayas, 2010), intihar eğilimi (Overholser, Adams, Lehnert ve Brinkman, 1995), intihar riski (Martin, Richardson, Bergen, Roeger ve Allison, 2005), intihar bilişleri (Cengiz, 2018) değişkenleri ile benlik saygısı arasında negatif yönde anlamlı ilişkilerin bulunduğu çalışma sonuçlarıyla benzer olduğu göze çarpmaktadır.

Ergenlik dönemindeki bireyler içinde bulunduğu dönemin getirdiği değişiklik ve talepler nedeniyle kendisini çaresiz ve karmaşık hissedebilmekte ve sonuç olarak karamsar duygulara kapılabilmektedir. Bu noktada benlik saygısının düşük olması ergenlik dönemindeki genç bireylerin depresyona girme gibi ruhsal sağlık sorunları ve bu nedenle de profesyonel yardım alma ihtiyacına yönelik gereksinimlerini artırmaktadır (Steinberg, 2017). Benzer biçimde, bireyin benlik saygısının düşük olması, kişilerin hassasiyetlerinin gelişmesine neden olup intihar davranışlarının ortaya çıkışına katkı sağlamaktadır (Harter ve Marold, 1994; O'Connor, Rasmussen ve Hawton, 2009). Yani, kişinin kendine yönelik olumsuz yüklemeleri intihar düşüncelerinin ortaya çıkışında rol oynayabilmektedir. Mevcut araştırmanın sonuçlarından yola çıkarak değerlendirildiğinde benlik saygısının yükselmesi durumunda intihar olasılığının düşmesi, 
beklenen bir sonuç olarak düşünebilir. Benlik saygısı yüksek olan bireylerin karşılaştıkları zorlu yaşam olayları ve sonuçlarıyla daha iyi başa çıkabilme ve olumsuz yaşam olaylarının etkilerinden kendilerini daha iyi koruyabilme olasılıklarının da yüksek olabileceği göz önünde bulundurulduğunda, bireylerin benlik saygılarının artırılması durumunda intihar eğilimlerinin azaltılabileceği söylenebilir.

Bu çalışmanın amacı doğrultusunda ortaya konan bir diğer bulgu sürekli öfke ve öfke ifade tarzlarından içe ve dışa yönelik öfke değişkenlerinin ergenlerin intihar olasılıklarını anlamlı düzeyde yordadığı şeklindedir. Bu durumda, öfkenin intiharın anlamlı yordayıcısı olduğuna yönelik alanyazındaki çalışma sonuçları (Batıün ve Şahin, 2003; Hisli Şahin, Onur ve Basım, 2008; McKinney, Hirsch ve Britton, 2017; Şimşek, 2003; Park vd., 2010) ile mevcut araştırmadan elde edilen sonuçların paralellik gösterdiği söylenebilir. Benzer biçimde, Şevik ve Özcan (2012) intihar girişimlerini inceledikleri çalışmada araştırmanın katılımcılarında intihar girişimini ani bir karar vererek gerçekleştirdiklerini belirten katılımcıların öfke düzey puanlarının da benzer şekilde yüksek olduğunun görüldüğünü rapor etmişlerdir. İntihar girişiminde bulunan ergenler ile gerçekleştirilen bir başka çalışmada ise sürekli öfke toplam puanları ile önceki intihar girişimi ve kendini yaralama davranışı varlığı arasında pozitif yönde istatistiksel anlamlı ilişkiler gözlemlenmiştir (Akın ve Berkem, 2012). Bu durumda özellikle lise öğrencilerinin öfke düzeyleri düşürüldüğünde intihar olasılığ ve girişiminin de azaltabileceğinin söylenebileceği düşünülmektedir. Ayrıca 15-21 yaş aralığındaki gençlerle gerçekleştirilen bir araştırmada (Reyes vd., 2015), öfke ve öfke ifade tarzlarının, intihar olasılığının yordayıcısı olduğu ve öfke ifade biçimlerinden öfke kontrolünün yani öfkeyi bireyin kendine yönelik yıkıcı bir şekilde deneyimlemesinin yerine yapıcı bir şekilde yönetebilmesinin bireylerde intihar olasıl1ğını düşürdüğü rapor edilmiştir. Mevcut araştırmada, öfke kontrolünün ergenlerin intihar olasılığının anlamlı bir yordayıcısı olmadığı bulunmuş olmasına rağmen ergenlerin öfke kontrolü ile intihar olasılığ 1 arasında negatif yönlü anlamlı bir ilişki olduğunun bulunması sonucunun Reyes ve arkadaşlarının (2015) araştırma sonuçlarını desteklediği söylenebilir. Diğer yandan ülkemizde üniversite öğrencileri ile gerçekleştirilen intihar olasılığının stresle baş etme ve öfke değişkenin beraber incelendiği bir araştırmada mevcut araştırmaya paralel şekilde intihar olasılığı puanları 
ile öfke içe ve öfke dışa puanları arasında pozitif yönlü anlamlı ilişki bulunurken, öfke kontrol puanları ile negatif yönde anlamlı ilişkiler saptanmıştır (Karataş ve Çelikkaleli, 2018). Bu çalışmalara ek olarak, ergenler ve yetişkinler ile gerçekleştirilen benlik saygısı, öfke ve intihar düşünceleri değişkenlerinin her üçünün birlikte ele alınarak incelendiği bir araştırmada (Jang vd., 2014) benlik saygısının ve öfkenin intihar düşüncelerinin birer yordayıcısı olduğu sonucuna varılmıştır. Bu çalışma ile mevcut araştırmanın bu yöndeki sonuçlarının tutarlılık gösterdiği söylenebilir.

Sonuç olarak bu araştırmada ergenlerde intihar eğilimi ve benlik saygısı ile öfke kontrol değişkenleri arasında negatif yönlü; benlik saygısı, sürekli öfke, içe yönelik öfke ve dışa yönelik öfke arasında ise pozitif yönlü ilişkiler bulunmuş ve öfke kontrolü dışında bu değişkenlerin intihar olasılığının anlamlı birer yordaycıları olduğu ortaya konmuştur. Bu araştırmada incelenen değişkenlerden biri olan benlik saygısının çok boyutlu değerlendirilmesi yerine toplam puan üzerinden değerlendirilmesi araştırmanın sınırlılıklarından birini oluşturmaktadır. Benlik saygısının akademik başarı, fiziksel ve kişilerarası ilişkiler gibi çok yönlü bir şekilde ele alınması durumunda intihar eğilimi açısından çok yönlü ve daha belirli ilişkilere yönelik bilgi elde edilebileceği düşünülmektedir. Bunun yanı sıra, boylamsal gerçekleştirilen çalışmalarda intihar düşüncelerinin özellikle ergenlik döneminde artış gösterdiği (Fergusson,Woodward, ve Horwood, 2000; Kerr, Owen, Pears ve Capaldi, 2008) göz önünde bulundurulduğunda yeni çalışmalar yapacak araştırmacıların bu araştırmada değişken olarak ele alınmayan yaş ve sınıf düzeyi açısından da intihar olasılığını değerlendirilmesi önemli görülmektedir. Aynı zamanda bu araştırmada benlik saygısı yüksek ve öfke düzeyi düşük ergenlerin intihar olasılıklarının da buna bağlı olarak azaltabileceği düşünüldüğünde koruyucu ve önleyici ruh sağlığı geliştirme amacı olan psikolojik danışmanlık ve rehberlik alanındaki uzmanların ergenlerdeki intiharı önlemek ve intihar olasılığını düşürmek amacıyla benlik saygılarının geliştirilmesi ve öfke düzeylerini düşürülmesine yönelik müdahale çalışmalarının yapmalarının yararlı olacağı düşünülmektedir. 
EXTENDED ABSTRACT

\title{
Suicide Probability in Adolescents: Relationship to Self-Esteem, and Anger
}

\author{
Fulya Cenkseven Önder - Ayten Bölükbaşı
}

Çukurova University

Suicide is defined commonly as self-harm behavior with the intention of killing oneself. Suicide can be affected by results of many psychological, sociological, economic and cultural factors (Hjelmeland et al., 2002). Suicide probability is an assessment of suicide risk of individuals including the components such as hopelessness, suicide ideation, negative self-evaluation and hostility. According to World Health Organization (2017), suicide was reported as the second leading death reason for the population aged between 15 and 29 years old. As for adolescents, suicide ideation which is also a subscale of suicide probability has the prevalence between $15 \%$ and $25 \%$ (Bridge, Goldstein, \& Brent, 2006). High school period has effects on physical, emotional, social development and also personality of adolescents (OrbachMikulincer, Gilboa-Schechtman, \& Sirota, 2003). On the other hand, one of the protective factors associated with suicide probability is self-esteem which can be defined as "worthiness towards selfconcept" of individuals (Rosenberg, 1965). Especially individuals with low level of self-esteem may consider attempting suicide as an escape from their cognitions and emotions which have stressful effect on their self-concept. In addition to this, one of the risk factors concerning suicide probability is anger. Anger can be defined as strong emotion or experience to end negative stimulant (Biaggio \& Maiuro, 1985). When anger is not expressed appropriately, the feelings of individuals can turn into devastating and self-blaming and also result in self-harming behaviors (Fox \& Hawton, 2004). Anger has been found to be a predictor of suicide behaviors (Kirkcaldy, Siefen, Urkin, \& Merrick, 2006), beside this, anger expression styles were also predictors of suicide thoughts (Park et al., 2010) in the literature. World Health Organization (2012) emphasized the importance of youths to be evaluated as high level suicide risk for preventing 
suicide because of globally rising suicide numbers nowadays. In literature review, it was seen that self-esteem and anger were predictors of suicide thoughts in a study (Jang et al., 2014). The aim of present study is to examine the relationships between suicide probability, self-esteem, trait-anger, anger-in, anger-out and anger control together and also to reveal the predictive power of self-esteem, trait-anger, and anger-in, anger-out and anger control on suicide probability among adolescents for the first time in Turkey.

In order to collect data "Suicide Probability" (Cull \& Gill, 1990), "Rosenberg Self-Esteem Scale" (Rosenberg, 1965) and "The State-Trait Anger Scale" (Spielberger, 1983) and "Personal Information Form" developed by researchers were used for research aims. This research was conducted on 426 high school students ( 214 females, 50.2\%; 212 males, 49.8\%). Participants ranged in age between 15 and 18 years and mean age of the participants was $15.89(\mathrm{sd}=.85)$. Pearson correlational analysis and multiple linear regression were conducted to reveal the relationships between variables. Results indicated that suicide probability was correlated positively with trait anger $(\mathrm{r}=.49, \mathrm{p}<.001)$, anger-in $(\mathrm{r}=.48, \mathrm{p}<.001)$ and anger-out $(\mathrm{r}=.48, \mathrm{p}<.001)$, however, self-esteem $(\mathrm{r}=-.56, \mathrm{p}<.001)$ and anger control $(\mathrm{r}=-$ $.26, \mathrm{p}<.001)$ were negatively correlated with suicide probability. In addition to this, according to results of multiple regression analysis, self-esteem, anger-in, anger-out, anger control variables together accounted for $48 \%$ of the variance in suicide probability $\left(\Delta R^{2}=.48, p<.001\right)$. According to standardized regression coefficients, self-esteem $(\Omega=-.43)$ was the strongest predictor of suicide probability accompanied by anger-out $(\beta=.19)$, trait anger $(\beta=.17)$, anger-in $(\beta=.14)$, anger control $(\Omega=.02)$. Lastly, t-test was performed for significance testing of regression coefficients and it was seen that all variables of the research apart from anger control $(t=.41$, p>.05) were found to be a significant predictor of suicide probability among adolescents in this study.

In conclusion, this study revealed that while suicide probability was correlated positively with trait anger, anger-in, and anger-out; suicide probability was correlated negatively with self-esteem, and anger control. Moreover, self-esteem was found to the strongest predictor of suicide probability accompanied by anger-out, trait anger, anger-in and anger control among adolescents. Finally, research variables except for anger 
control were found to be a significant predictor of suicide probability in this study. However, this study has some limitations. Firstly, self-esteem was evaluated globally and it was not measured multidimensional. When self-esteem can be evaluated in some domains such as academic success, physical and interpersonal relationships, more multiple relationships information regarding to suicide probability could be obtained. Lastly, it can be considered to give some suggestions to researchers and mental health professionals in the light of our study results, for example, developing and applying of protective and intervention group studies with the aim of increasing self-esteem and decreasing anger and thus, the decrease in suicide probability can be obtained for adolescents in future studies.

\section{Kaynakça / References}

Akın, E. ve Berkem, M. (2012). İntihar girişiminde bulunan ergenlerde öfke ve dürtüsellik. Marmara Medical Journal, 25, 148-52.

Batıgün, A.D. ve Şahin, N.H. (2003). Öfke, dürtüsellik ve problem çözme becerilerindeki yetersizlik, gençlik intiharlarının habercisi olabilir mi? Türk Psikoloji Dergisi, 18(51), 37-52.

Baumeister, R.F. (1990). Suicide as escape from self. Psychological Review, 97(1), 90-113.

Bernstein-Duprey, E., Oshri, A. ve Liu, S. (2018). Childhood maltreatment, self-esteem, and suicidal ideation in a low-ses emerging adult sample: The moderating role of heart rate variability. Archives of SuicideResearch, DOI: 10.1080/13811118.2018.1430640.

Bhar, S., Ghahramanlou-Holloway, M., Brown, G. ve Beck, A.T. (2008). Self-esteem and suicide ideation in psychiatric out patients. Suicide and Life-Threatening Behavior, 38(5), 511-516.

Biaggio, M.K. ve Maiuro, R.D. (1985). Recent advances in anger assessment. C. Spielberger ve J. Butcher (Yay.Haz.). Advances in personality assessment içinde (s.161-189). Hillsdale: Erlbaum.

Bridge, J., Goldstein, T. ve Brent, D. (2006). Adolescents suicide and suicidal behavior. Journal Child Psychol Psychiatry, 47, 372-94. 
Cengiz, A. (2018). Üniversite mezunu işsiz bireylerde benlik saygısı, psikolojik dayanıkllık, umutsuzluk ve intihar bilişleri arasındaki ilişkiler. Yayınlanmamış yüksek lisans tezi, Yakın Doğu Üniversitesi, Lefkoşa.

Cenkseven-Önder, F. (2018). Social support and coping styles in predicting suicide probability among turkish adolescents. Universal Journal of Educational Research, 6(1), 145 - 154.

Chatard, A., Selimbegović, L. ve Konan, P. K. (2009). Self-esteem and suicide rates in 55 nations. European Journal of Personality, 23, 19-32.

Coopersmith, S. (1967). The antecedents of self-esteem. W.H. Freemanand Company, San Francisco.

Creemers, D. H., Scholte, R. H., Engels, R. C., Prinstein, M. J. ve Wiers, R. W. (2012). Implicit and explicit self-esteem as concurrent predictors of suicidal ideation, depressive symptoms, and loneliness. Journal of Behavior Therapy and Experimental Psychiatry, 43(1), 638-646.

Cull, J. G. ve Gill, W. S. (1990). Suicide probability scale manual. Western psychological services, Los Angeles.

Çuhadaroglu, F. (1986). Ergenlerde benlik saygısı. Yayınlanmamış doktora tezi, Hacettepe Üniversitesi, Ankara.

Dahlen, E.R. ve Martin, R.C. (2005). The experience, expression, and control of anger in perceived social support. Personality and Individual Differences, 39(2), 391-401.

Daniel, S.S., Goldston, D.B., Erkanli, A., Franklin, J.C. ve Mayfield, A.M. (2009). Trait anger, anger expression, and suicide attempts among adolescents and young adults: A prospective study. Journal of Clinical Child and Adolescent Psychology, 38(5), 661-671.

Deffenbacher, J.L., Lynch, R.S., Oetting, E.R. ve Kemper, C.C. (1996). Anger reduction in early adolescents. Journal of Counseling Psychology, 43(2), 149-157.

Eskin, M., Ertekin, K., Dereboy, Ç. ve Demirkıran, F. (2007). Risk factors for and protective factors against adolescent suicidal behavior in Turkey. Crisis, 28, 131-139.

Fergusson, D.M., Woodward, L.J. ve Horwood, L.J. (2000). Risk factors and life processes associated with the onset suicidal behaviour during adolescence and early adulthood. Psychological Medicine, 30, 23-39. 
Fox, C. ve Hawton, K. (2004) Deliberate self-harm in adolescence. London: Jessica Kingsley Publishers.

Harter, S. (2012). The construction of the self: developmental and sociocultural foundations. New York, NY: Guilford.

Harter, S. ve Marold, D.B. (1994). Psychosocial risk factors contributing to adolescent suicidal ideation. G. G. Noam ve S. Borst (Yay. Haz.), Children, youth, and suicide: Developmental perspectives. New directions for child development içinde, (s. 71-91). San Francisco, CA: Jossey-Bass.

Hinduja, S. ve Patchin, J. W.(2010). Bullying, cyberbullying, and suicide. Archives of Suicide Studies, 14(3), 206-221.

Hisli Şahin, N., Onur, A. ve Basım, H. N. (2008). İntihar olasılığının, öfke, dürtüsellik ve problem çözme becerilerindeki yetersizlik ile yordanmas1. Türk Psikoloji Dergisi, 23(62), 79-88.

Hjelmeland, H., Hawton, K., Nordvik, H., Bille-Brahe, U., De Leo, D., Fekete, S., ... Wasserman, D. (2002). Why people engage in parasuicide: A cross-cultural study of intentions. Suicide Life ThreatBehavior, 32 (4), 380-93.

Jang, J., Park, J., Oh, K., Lee, K., Sig, M., Yoon, M., ... Chung, Y. (2014). Predictors of suicidal ideation in a community sample: Roles of anger, self-esteem, and depression. Psychiatry Research, 216(1), 7481.

Karataş, Z. ve Çelikkaleli, Ö. (2018). Beliren yetişkinlikte intihar olasıllı̆̆1: Stresle başetme, öfke ve cinsiyet açısından bir inceleme. Mersin Üniversitesi Ĕ̆itim Fakültesi Dergisi, 14(1), 450-462.

Kerr, D.C.R., Owen, L.D., Pears, K.C. ve Capaldi, D.M. (2008). Prevalence of suicidal ideation among boys and men assessed annually from ages 9 to 29 years. Suicide and Life-Threatening Behavior, 38, 390-402.

Kim, Y.H. (2003). Correlation of mental health problems with psychological constructs in adolescence: Final results from a 2-year study. International Journal Nursing Studies, 40, 115-124.

Kim, H.S. ve Kim, H.S. (2008). Risk factors for suicide attempts among Korean adolescents. Child Psychiatry Human Development, 39, 221-235.

Kirkcaldy, B.D., Siefen, G.R., Urkin, J. ve Merrick, J. (2006). Risk factors for suicidal behavior in adolescents. Minerva Pediatrica, 58, 443450 . 
Kuhlberg, J.A., Pena, J.B. ve Zayas, L.H. (2010). Familism, parent-adolescent conflict, self-esteem, internalizing behaviors and suicide attempts among adolescent Latinas. Child Psychiatry Human Development, 41, 425-440.

Lee, J., Choi, H., Kim, M., Park, C. ve Shin, D. (2009). Anger as a predictor of suicidal ideation in middle-school students in Korea: Gender difference in threshold point. Adolescence, 44(174), 433-446.

Lee, E. ve Mokuah, N. (2002). Meeting the mental health needs of Asians and pacific islander Americans. http://www.consumerstar. org/pubs/ MeetingAsian.pdf adresinden 01.01.2019 tarihinde erişildi.

Martin, G., Richardson, A.S., Bergen, H.A., Roeger, L. ve Allison, S. (2005). Perceived academic performance, self-esteem and locus of control as indicators of need for assessment of adolescent suicide risk: Implications for teachers. Journal of Adolescence, 28 (1), 75-87.

McGee, R., Williams, S. ve Nada-RajaS. (2001). Low self-esteem and hopelessness inchildhood and suicidal ideation in early adulthood. Journal of Abnormal Child Psychology, 29, 281-291.

McKinney, J.M.,.Hirsch, J.K. ve Britton, P.C. (2017). PTSD symptoms and suicide risk in veterans: Serial indirect effects via depression and anger. Journal of Affective Disorders. 214, 100-107.

Moskos, M., Olson, L., Halbern, S., Keller, T. ve Gray, D. (2005). Utah youth suicide study: psychologicalautopsy. Suicide Life Threat Behavior, 35 (5), 36-46.

O'Connor, R. C., Rasmussen, S. ve Hawton, K. (2009). Predicting deliberate self-harm in adolescents: A six month prospective study. Suicide Life Threat Behaviour, 39, 364-75.

Orbach, I., Mikulincer, M., Gilboa-Schechtman, E. ve Sirota, P. (2003). Mental pain and its relationship to suicidality and life meaning. Suicide and Life-Threatening Behavior, 33(3), 231-241.

Overholser, J.C., Adams, D.M., Lehnert, K.L. ve Brinkman, D. (1995). Selfesteem deficits and suicidal tendencies among adolescents. Child $\mathcal{E}$ Adolescent Psychiatry, 34(7), 919-928.

Özer, A.K. (1994). Sürekli öfke ve öfke ifade tarzı ölçekleri ön çalışması. Türk Psikoloji Dergisi, 9(31), 26-35. 
Park, Y.J., Ryu, H., Han, K., Kwon, J.H., Kim, H.K., Kang, H.C., ... Shin, H. (2010). Suicidal ideation in adolescents: An explanatory model using LISREL. Western Journal of Nursing Research, 32(2), 168-184.

Patterson, C. ve Hastings, P. (2007). Socialization in thecontext of family diversity. Grusec, J. ve Hastings, P. (Yay. Haz.). Handbook of socialization: Theory and research içinde (s. 328-351). New York: The Guilford Press.

Reyes, S.M.E., Cayubit, R.F.O., Angala, M.H., Bries, S.C. Capalungan, J.T. Docdoc, J., ... Rayos, K.M. (2015). North American Journal of Psychology, 17(1), 113-118.

Rosenberg, M. (1965). Society and the adolescent self-image. Princeton, NJ: Princeton University Press.

Sharma, B., Lee, T.H. ve Nam, E.W. (2017). Loneliness, insomnia and suicidal behavior among school-going adolescents in Western Pacific Island Countries: Role of violence and injury. International Journal of Environmental Research and Public Health, 14(7), 791-782.

Silva, R.J.D.S., Santos, F.A.L.D., Soares, N.M.M., Pardono, E. (2014). Suicidal ideation and associated factors among adolescents in North Eastern Brazil. The Scientific World Journal, 1-8. http://dx.doi.org/10.1155/2014/450943

Şimşek, E. (2003). Ergenlerde intihar düşüncesinin yordayıcıları. Yayımlanmamış Yüksek Lisans Tezi, Karadeniz Teknik Üniversitesi, Trabzon.

Spielberger, C. D. (1983). Assessment of anger: The state-trait anger scale. Advances in Personality Assessment, Hillsdale, 159-160.

Starner, T.M. ve Peters, R.M. (2004). Anger expression and blood pressure in adolescents. The Journal of School Nursing, 20 (6), 335-342.

Steinberg, L. (2017). Ergenlik. F. Çok (Yay. Haz.), Ergenlikte Psikososyal Sorunlar içinde (s.481-520). Ankara: İmge Kitapevi Yayınları.

Şevik, A. E. ve Özcan, H. (2012). Kastamonu ilinde intihar girişimlerinin psikososyal değerlendirmesi: Krizi önleme ve müdahale yöntemleri nasıl olmalı? Klinik Psikiyatri, 15, 153-165.

Tabachnick, B.G. ve Fidell, L.S. (2013). Using multivariate statistics (6th ed.), Boston: Allyn and Bacon.

Tuğcu, H. (1996). Normal ve depresif kişilerde çeşitli faktörlere göre intihar olasilığı. Doktora tezi, Hacettepe Üniversitesi, Ankara. 
Westefeld, J. S., Button, C., Haley, J. T., Kettmann, J. J, Macconnell, J., Sandil, R. ve Tallman, B. (2006). College student suicide: A call to action. Death Studies, 30 (10), 931-56.

World Health Organization (2012). Public health action for the prevention of suicide: A framework. 12 Şubat 2019 tarihinde https://apps.who.int/iris/bitstream/handle/10665/75166/9789241503570_eng.pdf;-jsessionid=A82F3FAED90DFD2CF66BFC882-

F3977FC? sequence $=1$ adresinden erişildi.

World Health Organization (2014). Preventing suicide a global imperative. Luxembourg: WHO Library Catalog. 12 Şubat 2019 tarihinde https://apps.who.int/iris/bitstream/handle/10665/131056/9789241564779_eng.pdf?sequence $=1$ adresinden erişildi.

World Health Organization (2017). Surveillance of suicide and suicide attempts. 25 Ocak 2019 tarihinde http://www.who.int/mental_health/suicide-prevention/en/ adresinden erişildi.

TÜİK (2015). Intihar istatistikleri 2015. 10 Ocak 2019 tarihinde http://www.tuik.gov.tr/HbPrint.do?id=21516 adresinden erişildi.

Vajani, M., Annest, J.L., Crosby, A.E., Alexander, J.D.ve Millet, L.M. (2007). Non fatal and fatal self-harm injuries among children aged 10-14 years - United Statesand Oregon, 2001-2003. Suicide Life Threat Behavior, 37(5), 493-506.

Wilburn, V.R. ve Smith, D.E. (2005). Stress, self-esteem, and suicidal ideation in late adolescents. Adolescence, 40 (157), 39-45.

Wild, L.G., Flisher, A.J. ve Lombard, C. (2004). Suicidal ideation and attempts in adolescents: Associations with depression and six domains of self-esteem. Journal of Adolescence, 27, 611-624.

Yount, M.A. (2000). Loneliness lack of perceived social support and the development of anger in adolescents. Yayımlanmamış Doktora Tezi, California State University. 


\section{Kaynakça Bilgisi / Citation Information}

Cenkseven-Önder, F. ve Bölükbaşı, A. (2019). Ergenlerde intihar olasılı̆̆g: Benlik saygısı ve öfke açısından incelenmesi. OPUS-Uluslararası Toplum Araştırmaları Dergisi, 10(17), 1522-1543. DOI: 10.26466/opus. 528723 